Публичная власть в современной России: проблемы и пер-

$\Pi 88$ спективы: сб. науч. тр. по материалам Всероссийской научно-практической конференции (г. Саратов, 4 декабря 2020 г.) / отв. ред. доктор юридических наук, доцент Ю.В. Соболева ; ФГБОУ ВО «Саратовская государственная юридическая академия» - Саратов: Изд-во ФГБОУ ВО «Саратовская государственная юридическая академия», 2020. - 412 c.

\title{
ISBN 978-5-7924-1654-3
}

Сборник содержит материалы Всероссийской научно-практической конференции «Публичная власть в современной России: проблемы и перспективы», проходившей в Саратовской государственной юридической академии 4 декабря 2020 года.

В докладах участников конференции - ученых, практических работников, а также обучающихся - рассматриваются вопросы реформирования органов публичной власти после внесения поправок в Конституцию Российской Федерации, иные актуальные проблемы совершенствования материального и процессуального административного законодательства, а также вопросы развития процесса нормотворчества в современной России в части проведения антикоррупционной экспертизы нормативных правовых актов и их проектов, обсуждается проблематика молодежного экстремизма, его профилактики в современном обществе.

Для преподавателей, аспирантов, обучающихся, ученых-юристов, практических работников, а также всех интересующихся проблемами реализации публичной власти в России.

Удк 342.5(063) ББК 67.400.6я43 


\section{Содержание}

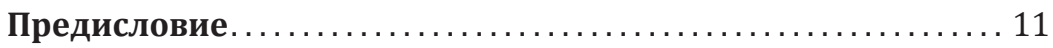

ЧАСТЬ 1

Вопросы реформирования органов публичной власти

после внесения поправок в Конституцию

Российской Федерации

\section{Соболева Ю.В.}

Развитие идей профессора Манохина В.М. об отраслевом регулировании в условиях конституционной реформы......... 13

Аникин С.Б., Пермяков А.И.

Централизация как основа организации исполнительной власти в Российской Федерации $\ldots \ldots \ldots \ldots \ldots \ldots \ldots \ldots \ldots \ldots \ldots \ldots \ldots \ldots \ldots$

Воронов А.М.

Публичное администрирование в современной России........ 22

Гришковец А.А.

Участие органов местного самоуправления в охране

общественного порядка в условиях новых

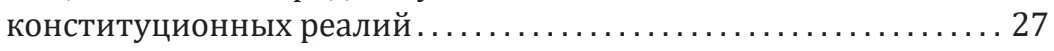

Кобзарь-Фролова М.Н.

Роль и функциональное назначение Правительства

Российской Федерации и органов исполнительной власти

Российской Федерации (законодательные новеллы) . ........ 40

Конин Н.М., Маторина Е.И.

О духовно-культурных правах и свободах человека и гражданина

в Российской Федерации . . . . . . . . . . . . . . . . . . . . . . 47

Севрюгин В.Е.

Конституционно-правовые аспекты через призму

административного права Российской Федерации

(к 25-й годовщине Конституции Российской Федерации) ....... 54

Абакумов Д.В.

К вопросу о главе исполнительной власти в РФ ............ 62

Ермошина Д.г.

«Публичная власть» - новое понятие

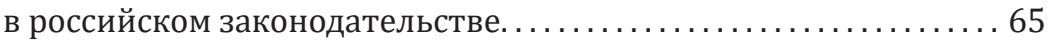




\title{
А.А. Гришковец
}

ведущий научный сотрудник

сектора административного права и административного процесса ФГБУН «Институт государства и права Российской академии наук», доктор юридических наук, профессор

e-mail:grishkovecz65@mail.ru

\section{УЧАСТИЕ ОРГАНОВ МЕСТНОГО САМОУПРАВЛЕНИЯ В ОХРАНЕ ОБЩЕСТВЕННОГО ПОРЯДКА В УСЛОВИЯХ НОВЫХ КОНСТИТУЦИОННЫХ РЕАЛИЙ}

\author{
A.A. Grishkovets \\ leading science researcher of department of administrative law \\ and administrative process of Institute of State and Law of Russian \\ academy of science, doctor of Law, Professor

\section{PARTICIPATION OF BODIES OF SELFGOVERNMENT IN GUARD OF PUBLIC REGIME IN CONDITIONS OF NEW CONSTITUTIONAL REALITIES}

\begin{abstract}
Аннотация. в статье рассматривается проблема участия органов местного самоуправления в охране общественного порядка, показано развитие законодательства, регулирующего это участие, и реальная практика его применения, дана авторская оценка изменения в статью 132 Конституции Российской Федерации, которым право органов местного самоуправления самостоятельно осуществлять охрану общественного порядка было исключено из числа вопросов местного значения.
\end{abstract}

Ключевые слова: местное самоуправление, муниципальные образования, общественный порядок, охрана общественного порядка, муниципальная милиция, полиция.

Законом Российской Федерации от 14 марта 2020 г. № 1-ФКЗ о поправке к Конституции Российской Федерации «О совершенствовании регулирования отдельных вопросов организации и функционирования публичной власти» ${ }^{1}$ компетенция органов местного самоуправления скорректирована. Из части 1 статьи 132 россий-

\footnotetext{
1 См.: Собр. законодательства Рос. Федерации. 2020. № 11, ч. 2, ст. 1416.
} 
ской Конституции была исключена норма, дававшая органам местного самоуправления право самостоятельно осуществлять охрану общественного порядка. Как представляется, изначально само появление указанной нормы было обусловлено надеждой на то, что со временем местное самоуправление в России укрепится и разовьется в полноценный уровень публичной власти, который наиболее приближен к населению, защищает его права и свободы, заботится о повседневных нуждах и чаяниях. Действительно, местное самоуправление составляет одну из важнейших частей механизма управления, который позволяет оптимально сочетать интересы и права человека и местные, региональные, общегосударственные интересы ${ }^{1}$.

Также стоит помнить, что российская Конституция 1993 года разрабатывалась и принималась в период масштабных социальных преобразований, которые проводились политическим руководством новой России с учетом опыта экономически развитых правовых демократических государств, тех же стран англо-саксонской правовой семьи (Австралия, Великобритания, Канада, Новая Зеландия, США), где имеется развитое местное самоуправление. Исторически там оно строилось, что называется «снизу», путем самоорганизации населения на уровне общин, графств, округов. Их жители в массе своей достаточно хорошо знали друг друга, причем знали лично, и поддерживали порядок в населенных собственными силами, тем более, что люди эти были еще и вооружены. Как известно, в тех же США право народа хранить и носить оружие даже специально закреплено в ратифицированной 17 декабря 1791 года поправке II к Конституции 1787 года. По замыслу отцов-основателей американской демократии, сформулированному в поправке, право народа хранить и носить оружие не подлежит ограничениям, поскольку хорошо организованная милиция необходима для безопасности свободного государства ${ }^{2}$. В традиции тех же США выборность населением шерифов в округах на 4 или на 6 лет. Их юрисдикция распространяется только на территорию графства (округа). Таким образом, руководитель полиции округа - шериф в своей деятельности зависит только от закона и от своих избирателей. На него

${ }^{1}$ См.: Кореневская С.М. Проблемы правового регулирования развития местного самоуправления. Труды молодых ученых: Субъективные права и законные интересы: теоретические основы и проблемы юридической защиты. Вып. 3, ч. 1 / под ред. Ю.Н. Старилова. Воронеж, 2002. С. 83.

2 См.: Конституции буржуазных государств. Учебное пособие. М., 1977. С. 47. 
практически невозможно оказать неформальное давление, что является серьезным антикоррупционным фактором ${ }^{1}$. Полицейская система США построена так, что «давление» на полицию городов и округов с точки зрения повышения эффективности ее работы оказывает не власть в лице вышестоящей структуры, а население муниципального образования. Поэтому единственный результат, к достижению которого стремится каждое полицейское агентство и небольшого городка (графства) и мегаполиса, - это удовлетворенность населения, налогоплательщика повседневной работой полиции ${ }^{2}$. Очевидно, что такая децентрализованная модель полицейской системы с точки зрения рядового гражданина выглядит вполне привлекательно. К сожалению, появление первоначальной, весьма демократичной редакции статьи 132 российской Конституции не учитывало отечественную практику построения местного самоуправления «сверху», когда само государство стимулировало создание на местах органов местного самоуправления, а у населения страны не было соответствующих демократических традиций. Закономерно поэтому, что конституционная норма, нацеленная на создание в постсоветской России смешанной модели полицейской системы государства, когда общественный порядок охраняется и государственными и местными силами охраны, на протяжении без малого 27 лет ее присутствия в тексте основного закона страны фактически не работала и органы местного самоуправления охрану общественного прядка самостоятельно не осуществляли.

Прежде чем оценить рассматриваемое изменение в статью 132 российской Конституции, необходимо четко определиться с тем, что есть общественный порядок и его охрана, как они понимаются в юридической науке. По мнению автора настоящей статьи, наиболее емкое и удачное во всех отношениях понятие «общественный порядок» было предложено К.С. Бельским. Ученый определяет его как морально-правовое состояние общества, при котором компетентные органы исполнительной власти путем полицейского надзора обеспечивают правопорядок и правомерное поведении граждан в общественных местах, свободное использование ими своих прав свобод, а также обустройство общественных мест, бла-

\footnotetext{
${ }^{1}$ См.: Быков A.B. Теоретические и прикладные проблемы функционирования национальных политических систем: автореф. дис. .... д-ра юрид. наук. М., 2008. C 31.

2 Там же. С. 33-34.
} 
гоприятствующее труду и отдыху граждан ${ }^{1}$. Как видно, К.С. Бельский не сводит общественный порядок к сугубо полицейской деятельности соответствующих силовых структур, в значительной мере ориентированных на применение государственного принуждения, а понимает его широко, включая в рассматриваемое понятие также позитивную деятельность администрации, тех самых «компетентных органов исполнительной власти». Справедливость последнего, имея в виду связь между обустройством общественных мест и общественным порядком, убедительно подтверждается опытом такого мегаполиса как, Нью-Йорк, в недавнем прошлом одного из наиболее криминальных городов США. Речь идет о так называемой теории «разбитых окон», которой стали руководствоваться мэр Нью-Йорка в период с 1994 по 2001 год Рудольф Джулиани и его команда. Теория проста, как правда. Она устанавливает жесткую корреляцию между разрухой и замусоренностью среды обитания, с одной стороны, и уровнем антиобщественного поведения, с другой. То есть, если местного пацана окружают заброшенные дома с размалеванными граффити стенами и разбитыми окнами, а на улицах громоздятся горы мусора, то волей-неволей его рука тянется к «косяку», ножу или пистолету2. Что касается охраны общественного порядка, то комментируя статью 132 Конституции, К.Ф. Шеремет справедливо отмечал, что в ней понятие «охрана общественного порядка» включает в себя, прежде всего, деятельность по обеспечению спокойствия и благополучия в общественных местах, недопущение и своевременное пресечение хулиганских и иных противоправных действий, привлечение к административной ответственности лиц, нарушающих правила поведения в общественных местах, во время уличных шествий и демонстраций, массовых гуляний, спортивных соревнований и т.П....Повседневная работа, обеспечивающая охрану общественного порядка, ложится на милицию общественной безопасности (местную милицию) ${ }^{3}$. Таким образом, общественный порядок сначала нужно обеспечить, а затем эффективно охранять его полицейскими силами.

Первая попытка законодательно закрепить полномочия органов местного самоуправления в сфере охраны общественного

\footnotetext{
1 См.: Бельский К.С. Феноменология административного права. Смоленск, 1995. С. 95.

2 См.: Сулькин О. Нью-Йоркский городовой// Итоги. 2012. № 51. С. 27.

3 См.: Конституция Российской Федерации. Комментарий / Под общей редакцией Б.Н. Топорнина, Ю.М. Батурина, Р.Г. Орехова. М., 1994. С. 564.
} 
порядка была предпринята в самом начале 90-х годов, когда еще существовал Союз ССР, а в России происходили бурные демократические преобразования. В Законе РФ от 6 июля 1991 года № 1550-I «0 местном самоуправлении в Российской Федерации» ${ }^{1}$ за органами местного самоуправления в зависимости от их статуса закреплялись отдельные полномочия по охране общественного порядка. Так, в части 8 статьи 54 данного нормативного правового акта среди полномочий поселковой, сельской администрации в области обеспечения законности, правопорядка, охраны прав и свобод граждан закреплялось такое полномочие, как утверждение в должности участковых инспекторов милиции, контроль их работы, оказание содействия органам милиции в осуществлении их функций. В части 8 статьи 76 к соответствующим полномочиям городской администрации относилось руководство городскими органами внутренних дел; создание за счет собственных и привлеченных средств дополнительных подразделений милиции общественной безопасности (местной милиции). Аналогичные полномочия предоставлялись также районной администрации (статья 65 Закона РФ от 6 июля 1991 года № 1550-I). Как видно, полномочия городской и районной администраций были достаточно широки. Очевидно, что наличие у органов местного самоуправления полномочий по охране общественного порядка предполагает, что у них есть достаточные финансовые ресурсы для их успешной реализации. Однако абсолютное большинство органов местного самоуправления такими ресурсами в тот период не обладало, как не обладает ими и в настоящее время.

Закон РФ от 18 апреля 1991 года № 1026-I «0 милиции» ${ }^{2}$ в статье 7 закрепил систему милиции, компонентами которой стали криминальная милиция и милиция общественной безопасности. Последняя рассматривалась как наиболее приближенное к нуждам граждан подразделение органов внутренних дел. Ее основными задачами являлись обеспечение охраны общественного порядка и обеспечение общественной безопасности, предупреждение и пресечение преступлений по которым производство предварительного следствия не обязательно, оказание в пределах своей компетенции помощи гражданам, предприятиям, организа-

\footnotetext{
1 См.: Ведомости Съезда нар. депутатов. РСФСР и Верховного Совета РСФСР. 1991. № 29, ст. 1010.

2 См.: Ведомости Съезда нар. депутатов РСФСР и Верховного Совета РСФСР. 1991. № 16, ст. 503.
} 
циям, учреждениям. Наряду с Законом РФ от 18 апреля 1991 года № 1026-I «0 милиции» правовую основу деятельности милиции общественной безопасности составляло Положение о ней, утвержденное указом Президента РФ от 12 февраля 1993 года № 209¹. Среди подразделений, входивших в состав милиции общественной безопасности, можно выделить: дежурные части; участковые инспектора милиции; изоляторы для временного содержания задержанных и заключенных под стражу лиц; специальные приемники для содержания лиц, арестованных в административном порядке; подразделения патрульно-постовой службы, в том числе отряды OMOH; подразделения государственной инспекции безопасности дорожного движения. Милиция общественной безопасности находилась в двойном подчинении. По вопросам организации охраны правопорядка и безопасности отделы внутренних дел муниципальных образований одновременно подчинялись вышестоящим органам внутренних дел и органам местного самоуправления. Их начальники назначались на должность и освобождались от должности по согласованию с соответствующими органами местного самоуправления.

Статья 9 «Милиция общественной безопасности» Закона РФ от 18 апреля 1991 года № 1026-I «О милиции» предусматривала возможность финансирования части милиции общественной безопасности за счет средств бюджетов субъектов Российской Федерации и местных бюджетов. Численность милиции общественной безопасности, финансируемой за счет средств данных бюджетов, устанавливалась соответственно органами власти субъекта Российской Федерации и органами местного самоуправления, но не ниже нормативов, утвержденных главой МВД России. Органы государственной власти субъектов Российской Федерации и органы местного самоуправления имели право за счет средств собственных бюджетов устанавливать дополнительную численность подразделений милиции общественной безопасности. Очевидно, что при таком подходе возникала значительная зависимость милиции общественной безопасности, финансируемой из региональных и местных бюджетов, от органов власти соответствующего уровня. Подобное положение в целом не способствовало объективности и беспристрастности в деятельности милиции общественной

\footnotetext{
1 См.: Собр. актов Президента и Правительства Рос. Федерации. 1993. № 7, ст. 562.
} 
безопасности.

Законодательство о местном самоуправлении обновилось в середине 90-х годов. Согласно пункту 8 части 2 статьи 6 Федерального закона от 28 августа 1995 года № 154-Ф3 «Об общих принципах организации местного самоуправления в РФ» ${ }^{1}$ к вопросам местного значения уже относится не только собственно охрана общественного порядка, но также организация и содержание муниципальных органов охраны общественного порядка, осуществление контроля за их деятельностью. Правда, в литературе отмечалось, что муниципальное образование, с одной стороны, обладало конституционным правом на охрану общественного порядка, а с другой - не могло его реализовать из-за отсутствия собственных сил правопорядка². Учитывая то обстоятельство, что Конституция Российской Федерации является правовым актом высшей юридической силой и действует непосредственно, подобное суждение представляется достаточно спорным. Дело, думается, не в отсутствии у муниципального образования собственных сил правопорядка, а в недостатке в муниципальном бюджете средств на их содержание и, кроме того, возможно, в отсутствии практической необходимости в создании таких сил, поскольку федеральные структуры (сначала милиция, а затем полиция) вполне успешно охраняли общественый порядка на территории муниципального образования. Однако, такую оценку разделяют далеко не все и у создания муниципальных органов охраны общественного порядка были активные сторонники. Так, характеризуя данные органы, А.М. Кононов в свое время весьма оптимистично и с немалым энтузиазмом отмечал, что это абсолютно новые для российской правовой системы субъекты правоохранительной деятельности. Их создание, по мнению указанного автора, позволит сформировать в Российской Федерации принципиально иную систему организации охраны общественного порядка, основанную на сочетании элементов централизации и децентрализации, даст возможность органам местного самоуправления реализовать свое конституционное право самостоятельно осуществлять охрану общественного порядка и тем самым будет способствовать развитию местного самоуправления и укреплению правопорядка в нашей

\footnotetext{
${ }^{1}$ См.: Собр. законодательства Рос. Федерации. 1995. № 35, ст. 3506.

2 См.: Муниципальное право Российской Федерации: учебник для бакалавров / под ред. А.В. Колесникова. 2-е изд., перераб. и доп. М., 2003. С. 111.
} 
стране ${ }^{1}$. Статус муниципальных органов охраны общественного порядка предполагалось закрепить в федеральном законе «Об основах организации муниципальных органов охраны общественного порядка (муниципальной страже)» в Российской Федерации», проект которого был разработан МВД России.

Не будет лишним отметить, что одно время перспективной задачей по совершенствованию государственного управления в области внутренних дел было формирование муниципальных органов охраны общественного порядка. В целях ее реализации по указу Президента РФ от 17 сентября 1998 года № $1115^{2}$ в ряде муниципальных образований проводился эксперимент по организации охраны общественного порядка органами местного самоуправления. Эксперимент охватывал территории Республики Карелия, Новгородской и Саратовской областей, а также отдельных муниципальных образований - г. Ставрополь (Ставропольский край), г.г. Иркутск и Братск (Иркутская область), г. Тольятти (Самарская область) и ряд других. На основании Указа Президента РФ от 2 июня 2000 года № $1011^{3}$ эксперимент был завершен. МВД России было поручено обобщить его результаты и использовать их в дальнейшей работе. К сожалению, в открытых источниках данные о таком обобщении, а тем более об использовании их в работе МВД России обнаружить не удается, с чем вряд ли можно согласиться. Правда, из автореферата докторской диссертации того же А.М.Кононова, защищенной им в 2000 году в Академии управления МВД России, можно узнать, что, как показал эксперимент, в настоящее время в стране еще не сложились должные социально-политические, социально-экономические и организационные условия для самостоятельного осуществления органами местного самоуправления охраны общественного порядка ${ }^{4}$. Как известно, эксперимент не получил дальнейшего развития. Поэтому, можно

1 См.: Кононов А.М. Теоретические основы организации муниципальных органов охраны общественного порядка в Российской Федерации: автореф дис.... д-ра юрид. наук. М., 2000. С. 6-7.

2 См.: Указ Президента РФ от 7 сентября 1998 г. № 1115 «0 проведении в ряде муниципальных образований эксперимента по организации охраны общественного порядка органами местного самоуправления» // Собр. законодательства Рос. Федерации. 1998. № 38, ст. 4783.

3 См.: Указ Президента Российской Федерации от 2 июня 2000 года № 1011 «0 завершении эксперимента по организации охраны общественного порядка органами местного самоуправления» // Собр. законодательства Рос. Федерации. 2000. № 23, ст. 2386.

4 См.: Кононов А.М. Указ. соч. С. 15. 
уверенно говорить, что политическое руководство страны пришло к выводу о принципиальной неприемлемости, по крайней мере на современном этапе общественного развития, организации охраны общественного порядка органами местного самоуправления. Правда, несмотря на то, что уже в 2000 году эксперимент был прекращен, в Основных положениях государственной политики в области местного самоуправления, утвержденных указом Президента Российской Федерации от 15 октября 1999 года № 370 ${ }^{1}$, тем не менее, отмечалось, что в Конституции Российской Федерации среди важнейших вопросов местного значения названо осуществление охраны общественного порядка. Кроме того, среди основных направлений и задач государственной политики в области создания условий для реализации органами местного самоуправления своих полномочий на самостоятельное решение вопросов местного значения значилось создание условий для осуществления ими охраны общественного порядка. Таким образом, конституционное право органов местного самоуправления на участие в охране общественного порядка под сомнение вроде бы не ставилось, но и реальным содержанием оно не наполнялось. В 2020 году соответствующее изменение в статью 132 российской Конституции поставило окончательную точку в деле о праве органов местного самоуправления самостоятельно осуществлять охрану общественного порядка. Такое право им больше не предоставляется.

Повторимся, первоначальная редакция части 1 статьи 132 российской Конституции предусматривала, что органы местного самоуправления самостоятельно осуществляют охрану общественного порядка. Конституционные нормы первоначально были конкретизированы в Федеральном законе от 28 августа 1995 года № 154-Ф3 «Об общих принципах организации местного самоуправления в Российской Федерации», а позднее, хотя и в несколько измененном виде, подтверждаются в пришедшем ему на смену Федеральном законе от 6 октября 2003 года № 131-Ф3 «Об общих принципах организации местного самоуправления в Российской Федерации»². Так, среди вопросов местного значения муниципального района (пункт 8 части 1 статьи 15) и муниципального,

1 См.: Указ Президента РФ от 15 октября 1999 г. № 370 «Об утверждении Основных положений государственной политики в области развития местного самоуправления в Российской Федерации» // Собр. законодательства Рос. Федерации. 1999. № 42, ст. 5011.

${ }^{2}$ См.: Собр. законодательства Рос. Федерации. 2003. № 40, ст. 3822. 
городского округа (пункт 9 части 1 статьи 16) закрепляется такой вопрос, как организация охраны общественного порядка на соответствующей территории муниципальной милицией. Реализация права органов местного самоуправления на самостоятельное осуществление функции охраны общественного порядка (и обязанности его обеспечения), подчеркивал один из разработчиков Федерального закона от 6 октября 2003 года № 131-Ф3 депутат Государственной Думы В.С. Мокрый, требует реорганизации милиции общественной безопасности. Часть ее функций должна быть передана создаваемым органами местного самоуправления подразделениям муниципальной милиции. Создание муниципальных органов охраны общественного порядка, по мнению указанного автора, должно осуществляться поэтапно, в том числе путем совершенствования законодательства об участии граждан в охране общественного порядка, выделения органами местного самоуправления соответствующих штатных должностей и их финансирования ${ }^{1}$. Кроме того, к вопросам местного значения отнесено предоставление помещения для работы на обслуживаемом административном участке муниципального образования сотруднику, замещающему должность участкового уполномоченного полиции (пункт 33.1 части 1 статьи 15 и пункт 9.1 части 1 статьи 16). Хотя Законом РФ о поправке к Конституции РФ от 14 марта 2020 года № 1-ФКЗ «О совершенствовании регулирования отдельных вопросов организации и функционирования публичной власти» указанное конституционное положение было исключено из числа вопросов местного значения, однако в Федеральный закон от 6 октября 2003 года № 131-Ф3 соответствующие изменения пока не внесены.

Европейская Хартия местного самоуправления ETS № 122 от 15 октября 1985 года² специально не выделяет какие-либо полномочия органов местного самоуправления в сфере охраны общественного порядка. В статье 1 Хартии лишь закрепляется, что основные полномочия органов местного самоуправления устанавливаются Конституцией и законом. Таким образом, соответствующие полномочия устанавливаются исключительно в национальном законодательстве той или иной страны, исходя из сложившихся традиций, уровня правосознания и правовой культуры

${ }^{1}$ См.: Мокрый B.C. Местное самоуправление в Российской Федерации как институт публичной власти и гражданского общества: автореф дис. ... д-ра юрид. наук. М., 2003. С. 42.

${ }^{2}$ См.: Собр. законодательства Рос. Федерации. 1998. № 36, ст. 4466. 
в обществе, а также политики проводимой демократически сформированными органами государства.

В соответствии с частью 1 Федерального закона от 7 февраля 2011 года № 3-Ф3 «0 полиции» ${ }^{1}$ российская полиция в частности предназначена для охраны общественного порядка. В части 1 статьи 10 данного нормативного правового акта устанавливается, что при осуществлении своей деятельности полиция взаимодействует, в том числе с органами местного самоуправления. Полиция при выполнении возложенных на нее обязанностей может использовать возможности муниципальных органов, которые должны оказывать ее содействие. В свою очередь, полиция в пределах своих полномочий содействует муниципальным органам в обеспечении защиты прав и свобод граждан, соблюдения законности и правопорядка. Как видно, на муниципальных органах и полиции лежат взаимные обязанности по взаимодействию друг с другом, включая такую сферу взаимодействия, как обеспечение общественного порядка.

Практика показывает, что любые правонарушения и правонарушения в сфере общественного порядка исключением не являются, всегда эффективнее профилактировать, т.е. не допускать, чем пресекать и наказывать лиц, виновных в их совершении. И органы местного самоуправления могут вносить свой весомый вклад в решение данной проблемы. Так, согласно части 2 статьи 7 Федерального закона от 23 июня 2016 года № 182-Ф3 «Об основах системы профилактики правонарушений в Российской Федерации» ${ }^{2}$ органы государственной власти субъектов РФ разрабатывают государственные программы субъектов Российской Федерации в сфере профилактики правонарушений, а согласно части 2 той же статьи указанного федерального закона органы местного самоуправления вправе разрабатывать муниципальные программы в сфере профилактики правонарушений. Разработка соответствующих программ представляется перспективным направлением деятельности органов местного самоуправления в сфере обеспечения охраны общественного порядка.

Для населения любой территории исключительную значимость имеет обеспечение безопасности в общественных местах. Выходя на прогулку, в магазин или направляясь на работу, т.е. покидая свое жилище и оказываясь в общественных местах, люди

\footnotetext{
${ }^{1}$ См.: Собр. законодательства Рос. Федерации. 2011. № 7, ст. 900.

2 См.: Собр. законодательства Рос. Федерации. 2016. № 26, ч. 1, ст. 3851.
} 
должны чувствовать, что их жизнь, здоровье, имущество надежно защищены от любых противоправных посягательств и общественный порядок, безусловно, обеспечивается и охраняется на должном уровне. Очевидно, что наибольший положительный эффект в области охраны общественного порядка может быть достигнут только тогда, когда наряду с занимающейся этим делом профессионально полицией, на данном направлении ее деятельности задействованы широкие слои населения, организованные в коллективы социально активные граждане. Правовую базу здесь составляет Федеральный закон от 2 апреля 2014 года № 44-Ф3 «Об уча-

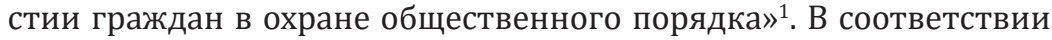
с частью 2 статьи 6 указанного нормативного правового акта органы местного самоуправления в соответствии с законодательством и муниципальными правовыми актами оказывают поддержку гражданам и их объединениям, участвующим в охране общественного порядка, создают условия для деятельности народных дружин. Данная норма корреспондируется с аналогичными по содержанию нормами профильного Федерального закона от 6 октября 2003 года № 131-Ф3 «Об общих принципах организации местного самоуправления в Российской Федерации». Так, среди вопросов местного муниципального района (п. 33 части 1 статьи 15 Федерального закона) и муниципального, городского округа (пункт 37 части 1 статьи 16 Федерального закона) закрепляется такой вопрос, как оказание поддержки гражданам и их объединениям, участвующим в охране общественного порядка, создание условий для деятельности народных дружин.

В качестве заключения. Оптимистические прогнозы отдельных авторов относительно создания муниципальных органов охраны общественного порядка не оправдались. Думается, тому же А.М.Кононову в свое время следовало бы более реалистично и осторожно оценивать ситуацию, тем более в докторской диссертации, учитывать отечественные традиции местного самоуправления и финансовые возможности муниципальных образований, существующую в России исторически централизованную полицейскую систему. К сожалению, он этого не сделал. Кстати сказать, было бы интересно узнать, как спустя 20 лет после защиты своей докторской диссертации на тему «Теоретические основы организации муниципальных органов охраны общественного порядка в Российской

\footnotetext{
${ }^{1}$ См.: Собр. законодательства Рос. Федерации. 2014. № 14, ст. 1536.
} 
Федерации» А.М.Кононов оценивает внесенное в 2020 году изменение в статью 132 российской Конституции. Считает ли он, что, исходя из современных реалий, изменение оправдано, либо нет, и следовало бы сохранить за органами местного самоуправления на конституционном уровне право самостоятельно осуществлять охрану общественного порядка, а лишение их этого права ошибочно и интересам тех же местных сообществ не отвечает? Постановка обозначенных вопросов - это приглашение к дальнейшей дискуссии, в которую, хочется верить, включится не только А.М.Кононов, но и другие заинтересованные представители ведомственной науки, выходцы из системы МВД России, а также ученые-юристы, исследующие проблемы местного самоуправления.

Думается, исключение из статьи 132 российской Конституции положения о том, что органы местного самоуправления самостоятельно осуществляют охрану общественного порядка, совсем не означает, что они перестали участвовать в этом во всех отношениях важном и значимом для населения соответствующей территории деле, поскольку муниципальные органы охраны общественного порядка не были созданы и создаваться уже не будут. Конституционное изменение позволило привести правовое регулирование в соответствие с ранее сложившейся в стране практикой организации охраны общественного порядка, отражавшей традицию централизации сил правоохраны. При этом в соответствии с федеральными законами органы местного самоуправления сохраняют достаточно широкие возможности принимать участие в охране общественного порядка, пусть и не создавая для этого соответствующих муниципальных органов, той же муниципальной милиции или муниципальной стражи. Органам местного самоуправления следует сосредоточиться на обеспечении такой составляющей общественного порядка, как обустройство общественных мест, благоприятствующее труду и отдыху граждан, и руководствоваться в этом деле той же теорией «разбитых окон». 